\title{
TEORES FOLIARES DOS MACRONUTRIENTES CATIÔNICOS E SUAS RELAÇÕES COM O SÓDIO EM PLANTAS DE MILHO SOB ESTRESSE SALINO
}

\author{
LEAF CONTENTS OF CATIONIC MACRONUTRIENTS AND THEIR \\ RELATIONSHIPS WITH SODIUM IN MAIZE PLANTS UNDER SALINE STRESS
} Giovanni de Oliveira Garcia ${ }^{1}$; Paulo Afonso Ferreira ${ }^{2}$; Glauco Vieira Miranda
Júlio Cezar Lima Neves ${ }^{4}$; Willian Bucker Moraes ${ }^{5}$ Delfran Batista dos Santos

\begin{abstract}
RESUMO
O estresse salino representa um dos mais sérios fatores que limitam o crescimento e a produção das culturas, induzindo a modificações morfológicas, estruturais e metabólicas nas plantas superiores. Com objetivo avaliar os efeitos da salinidade do solo sobre os teores nutricionais dos macronutrientes catiônicos e suas relações com o sódio em uma variedade de milho, foi conduzindo em lisímetros de drenagem sob condições de casa de vegetação, montado em delineamento inteiramente casualizado com sete tratamentos, sendo um irrigado com água doce e sem lixiviação e seis irrigados com água salina de 1,2 $\mathrm{dS} \mathrm{m}^{-1}$, com frações de lixiviação de 40, 30, 20, 15,10 e $5 \%$ da lâmina de irrigação aplicada, e três repetições. Os efeitos da salinidade do solo sobre a nutrição mineral da cultura do milho foram avaliados determinando o teor foliar dos macronutrientes catiônicos e suas relações com o sódio aos 30, 60, 90 e 120 dias após o plantio. No cultivar avaliado, o aumento da salinidade do solo decorrente da irrigação com água salina elevou os teores de sódio, as relações $\mathrm{Na}^{+} / \mathrm{Ca}^{2+}, \mathrm{Na}^{+} / \mathrm{Mg}^{2+}, \mathrm{Na}^{+} / \mathrm{K}^{+}$e reduziu os teores de cálcio, magnésio e potássio, refletindo dessa forma, o desequilíbrio nutricional causado pelo estresse nutricional conseqüente do estresse salino progressivo.
\end{abstract}

Palavras-Chave: Salinidade do solo, Zea mays L., nutrição mineral.

\section{SUMMARY}

The saline stress is one of the most detrimental factors restraining the growth and the yield of the crops, as inducing the morphologic, structural and metabolic modifications, in the agronomic plants. The effects of soil salinity on the nutritional contents of cationic macronutrients and their relationships with sodium were studied, by using a maize variety cropped in drainage lysimeters under greenhouse conditions. The experiment was set up in an entirely randomized experimental design with seven treatments: one irrigated with fresh water and without leaching; and six ones irrigated with saline water of $1.2 \mathrm{dS} \mathrm{m}^{-1}$ and leaching fractions of 40, 30,20,15, 10 and 5\% of the applied irrigation depth, and three replicates. The effects of the soil salinity on the mineral nutrition of the maize crop were evaluated, by determining the leaf contents of the cationic macronutrients and their relationships with sodium at 30, 60, 90 and 120 days after planting. The increased soil salinity promoted by irrigation with saline water also increased the sodium contents, the relationships $\mathrm{Na}^{+} / \mathrm{Ca}^{2+}, \mathrm{Na}^{+} / \mathrm{Mg}^{2+}, \mathrm{Na}^{+} / \mathrm{K}^{+}$, but reduced the contents of calcium, magnesium and potassium, therefore characterizing the unbalance and the nutritional stress consequent to the progressive saline stress.

Key words: Soil salinity, Zea mays L., mineral nutrition.

\footnotetext{
1 Universidade Federal do Espírito Santo, Centro de Ciências Agrárias, Alegre, ES. 29.500-000. E-mail: giovanni@ cca.ufes.br 2 Universidade Federal de Viçosa, Departamento de Engenharia Agrícola, Viçosa, MG.

3 Universidade Federal de Viçosa, Departamento de Fitotecnia, Viçosa, MG.

4 Universidade Federal de Viçosa, Departamento de Solos, Viçosa, MG.

5 Universidade Federal do Espírito Santo, Alegre, ES.

6 Escola Agrotécnica Federal do Senhor do Bonfim, Senhor do Bonfim, BA.
}

Fecha de Recepción: 11 Mayo 2007

Fecha de Aceptación: 05 Julio 2007 


\section{INTRODUÇÃO}

A resposta das plantas à salinidade é um fenômeno complexo, envolvendo alterações morfológicas e de crescimento, além de processos fisiológicos, bioquímicos e nutricionais (Cramer et al., 1994). Assim, a sobrevivência das plantas em ambientes salinos pode exigir processos adaptativos envolvendo a absorção, transporte e distribuição de íons nos vários órgãos da planta e sua compartimentação dentro das células (Munns \& Termaat, 1986).

A maioria das culturas evoluíram sob condições de baixa salinidade do solo. Os mecanismos desenvolvidos para absorver, transportar e utilizar os nutrientes minerais presentes em substratos não salinos podem não ser eficazes em condições salinas. Nessas condições a concentração dos íons de $\mathrm{Na}^{+}$ e/ou de $\mathrm{Cl}^{-}$, freqüentemente, excedem as concentrações de macro e micronutrientes (Grattan \& Grieve, 1999). Quando o conteúdo de $\mathrm{NaCl}$ no solo é alto, a absorção de nutrientes minerais, especialmente o $\mathrm{NO}^{3-}, \mathrm{K}^{+}$e $\mathrm{Ca}^{2+}$ é reduzida (Larcher, 2000).

A disponibilidade de nutrientes para as plantas em ambientes salinos é afetada por muitos fatores no ambiente solo - planta. $\mathrm{O}$ pH do solo influencia na disponibilidade dos nutrientes, a concentração e as relações entre os elementos podem influenciar a absorção e o transporte, em particular, de um nutriente e indiretamente pode afetar a absorção e a translocação de outros (Grattan \& Lamenta, 1994).

Em ambientes salinos, o $\mathrm{NaCl}$ é o sal predominante e o que causa maiores danos as plantas. Os efeitos sobre a nutrição mineral são decorrentes, principalmente, da toxicidade dos íons em razão da absorção excessiva do $\mathrm{Na}^{+}$e $\mathrm{Cl}^{-}$, e do desequilibro nutricional causado pelos distúrbios na absorção ou distribuição dos nutrientes (Yahya, 1998). O excesso de $\mathrm{Na}^{+}$e, sobretudo, um excesso de $\mathrm{Cl}^{-}$ no protoplasma ocasionam distúrbios em relação ao balanço iônico $\left(\mathrm{K}^{+}\right.$e $\mathrm{Ca}^{2+}$ em relação ao $\left.\mathrm{Na}^{+}\right)$, bem como os efeitos específicos destes íons sobre as enzimas e membranas (Flores, 1990).

Em condições não salinas, o citossol das células de plantas não halófitas contem cerca de 1,0 a 3,0 dag $\mathrm{kg}^{-1}$ de $\mathrm{K}^{+}$e 0,01 a $0,1 \mathrm{dag} \mathrm{kg}^{-1} \mathrm{de}$ $\mathrm{Na}^{+}$, um ambiente iônico no qual muitas enzimas alcançam o seu ótimo. Os efeitos de toxicidade iônica ocorrem, quando as concentrações de íons prejudiciais, particularmente $\mathrm{Na}^{+}, \mathrm{Cl}^{-}$ou $\mathrm{SO}_{4}{ }^{-2}$, acumulam-se nas células. Uma alta relação $\mathrm{Na}^{+}$/
$\mathrm{K}^{+}$bem como a concentração elevada de sais totais inativa as enzimas e inibem a síntese protéica (Taiz \& Zeiger, 2004).

Os íons inorgânicos desempenham importante papel na preservação do potencial hídrico do vegetal. Portanto, os mecanismos que resultam no excesso de absorção iônica e exclusão de $\mathrm{Na}^{+} \mathrm{e} \mathrm{Cl}^{-}$de tecidos metabolicamente ativos da parte aérea das plantas, podem ser responsáveis pela tolerância das culturas ao estresse salino (Cheeseman, 1998). Esta exclusão pode ser efetuada por acumulação preferencial de íons em tecidos relativamente tolerantes da raiz ou da parte aérea (Boursier et al., 1987).

O presente trabalho teve como objetivo estudar o efeito da salinidade da solução do solo sobre os teores dos macronutrientes catiônicos e suas relações com o sódio, em uma variedade de milho.

\section{MATERIAIS E MÉTODOS}

O trabalho foi conduzido em 21 lisímetros de drenagem de 1,0 $\mathrm{m}$ de largura, 1,40 m de comprimento e $0,80 \mathrm{~m}$ de profundidade, construídos dentro de uma casa de vegetação no campus da Universidade Federal de Viçosa, Viçosa - MG, com coordenadas geográficas de $20^{\circ} 45^{\prime}$ de latitude Sul, $42^{\circ} 45^{\prime}$ de longitude Oeste e altitude de $651 \mathrm{~m}$. A área total ocupada pelos lisímetros era de $124,6 \mathrm{~m}^{2}$ (7,0 $\mathrm{m}$ de largura por 17,80 $\mathrm{m}$ de comprimento) e cada lisímetro era provido de drenagem de fundo de caixa ligada a um dispositivo para a coleta do efluente. A espessura do perfil do solo, dentro da caixa era de $0,70 \mathrm{~m}$.

O solo utilizado no preenchimento dos lisímetros foi coletado no perfil natural de um Argissolo Vermelho Escuro Eutrófico $\mathrm{Tb}$ existente na base da Serra de São Geraldo, no município de São Geraldo, MG, distante de, aproximadamente, 21 $\mathrm{km}$ de Viçosa. Antes do plantio, devido ao excesso de sais do solo nos lisímetros que receberiam as irrigações com água salina, foi feita uma intensa lixiviação nos mesmos até atingir, aproximadamente, $1,00 \mathrm{dS} \mathrm{m} \mathrm{m}^{-1}$ no extrato de saturação, empregando água doce.

A caracterização química e físico-química do solo (Tabela 1) foi feita nos laboratórios de Análise de Física do Solo e de Água e Solo dos Departamentos de Solo e de Engenharia Agrícola, respectivamente. As análises químicas constituíramse na determinação dos teores de P disponível, 
K, Ca, Mg, Na, Al trocável, H+Al, CTC efetiva, CTC total, $\mathrm{pH}$, saturação de bases, porcentagem de sódio trocável, índice de saturação por alumínio e fósforo remanescente. Na análise física do solo, foram efetuadas as determinações de: massa específica, pelo método da proveta; partículas, pelo método do balão volumétrico; análise granulométrica, pelo método da pipeta (Embrapa, 1997).

O experimento foi montado no delineamento inteiramente casualizado com sete tratamentos e três repetições, perfazendo um total de 21 unidades experimentais. Os sete tratamentos constituíram-se de uma irrigação com água doce (sem lixiviação) e seis irrigados com água salina de $1,2 \mathrm{dS} \mathrm{m}^{-1}$, com frações de lixiviação de 40,30, 20, 15, 10 e $5 \%$ da lâmina de irrigação aplicada.

A água salina utilizada nas irrigações (Tabela 2) foi preparada em um reservatório com capacidade de $1000 \mathrm{~L}$ mediante a adição de $\mathrm{NaCl}$ e $\mathrm{CaCl}_{2}$ em quantidades necessárias para se obter uma condutividade elétrica (CEai) de $1,20 \mathrm{dS} \mathrm{m}^{-1}$ e uma relação iônica, em peso, equivalente a $3 \mathrm{Na} 2 \mathrm{Ca}$, relação

Tabela 1

Características físico-químicas do solo utilizado no preenchimento dos lisímetros de drenagem

\begin{tabular}{|l|c|l|c|}
\hline \multicolumn{1}{|c|}{ Característica } & Valor & \multicolumn{1}{|c|}{ Característica } & Valor \\
\hline Areia grossa $\left(\mathrm{dag} \mathrm{kg}^{-1}\right)$ & 18,4 & $\mathrm{Ca}^{2+}\left(\mathrm{cmol}_{\mathrm{c}} \mathrm{dm}^{-3}\right)$ & 2,70 \\
\hline Areia fina $\left.(\mathrm{dag} \mathrm{kg})^{-1}\right)$ & 9,8 & $\mathrm{Mg}^{2+}\left(\mathrm{cmol}_{\mathrm{c}} \mathrm{dm}^{-3}\right)$ & 0,60 \\
\hline Silte $\left(\mathrm{dag} \mathrm{kg}^{-1}\right)$ & 17,0 & $\mathrm{Al}^{3+}\left(\mathrm{cmol}_{\mathrm{c}} \mathrm{dm}^{-3}\right)$ & 0,00 \\
\hline Argila $\left(\mathrm{dag} \mathrm{kg}{ }^{-1}\right)$ & 54,8 & $\mathrm{H}+\mathrm{Al}\left(\mathrm{cmol}_{\mathrm{c}} \mathrm{dm}^{-3}\right)$ & 0,33 \\
\hline Densidade do solo $\left(\mathrm{kg} \mathrm{dm}^{-3}\right)$ & 1,20 & Soma de Bases $\left(\mathrm{cmol}_{\mathrm{c}} \mathrm{dm}^{-3}\right)$ & 3,88 \\
\hline Densidade de partículas $\left(\mathrm{kg} \mathrm{dm}^{-3}\right)$ & 2,63 & $\mathrm{CTC}$ efetiva $\left(\mathrm{cmol}_{\mathrm{c}} \mathrm{dm}^{-3}\right)$ & 3,88 \\
\hline Porosidade total $\left(\mathrm{dm}^{3} \mathrm{dm}^{-3}\right)$ & 0,54 & CTC total $\left(\mathrm{cmol}_{\mathrm{c}} \mathrm{dm}^{-3}\right)$ & 4,21 \\
\hline $\mathrm{pH}$ em água & 5,9 & Saturação por alumínio $(\%)$ & 0,0 \\
\hline $\mathrm{Na}^{+}\left(\mathrm{mg} \mathrm{dm}^{-3}\right)$ & 99,0 & Saturação por bases $(\%)$ & 92,0 \\
\hline $\mathrm{P}\left(\mathrm{mg} \mathrm{dm}{ }^{-3}\right)$ & 4,2 & PST $(\%)$ & 10,1 \\
\hline $\left.\mathrm{K}^{+}(\mathrm{mg} \mathrm{dm})^{-3}\right)$ & 60,0 & $\mathrm{P}-$ rem $\left(\mathrm{mg} \mathrm{L}^{-1}\right)$ & 31,4 \\
\hline
\end{tabular}

PST - Porcentagem de sódio trocável; P - rem - Fósforo remanescente.

Tabela 2

Características médias da água utilizada na irrigação da cultura do milho durante o período experimental

\begin{tabular}{|l|c|c|}
\hline \multirow{2}{*}{ Característica } & \multicolumn{2}{|c|}{ Valor } \\
\cline { 2 - 3 } & Água salina & Água doce \\
\hline Condutividade elétrica $\left(\mathrm{dS} \mathrm{m}^{-1}\right)$ & 1,20 & 0,06 \\
\hline Concentração de sódio $\left(\mathrm{cmol}_{\mathrm{c}} \mathrm{L}^{-1}\right)$ & 0,4436 & 0,0002 \\
\hline Concentração de cálcio $\left(\mathrm{cmol}_{\mathrm{c}} \mathrm{L}^{-1}\right)$ & 0,2875 & 0,0167 \\
\hline Concentração de cloro $\left(\mathrm{cmol}_{\mathrm{c}} \mathrm{L}^{-1}\right)$ & 0,0141 & 0,0000 \\
\hline Concentração de magnésio $\left(\mathrm{cmol}_{\mathrm{c}} \mathrm{L}^{-1}\right)$ & 0,0534 & 0,0103 \\
\hline Concentração de potássio $\left(\mathrm{cmol}_{\mathrm{c}} \mathrm{L}^{-1}\right)$ & 0,0186 & 0,0192 \\
\hline RAS $\left(\mathrm{cmol}_{\mathrm{c}} \mathrm{L}^{-1}\right)^{0,5}$ & 1,0744 & 0,0002 \\
\hline pH & 6,70 & 6,20 \\
\hline
\end{tabular}


esta predominante nas águas salinas utilizadas na irrigação no nordeste do país (Medeiros, 1992).

Os dados de temperatura, umidade relativa do ar, radiação solar incidente e velocidade do vento foram coletados numa estação meteorológica localizada dentro da casa de vegetação e os valores da evapotranspiração real (ETr) foram corrigidos pontualmente, em cada lisímetro, por meio do balanço de água do solo com base numa freqüência de irrigação de dez dias (Figura 1 A, B, C, D e E).
As lâminas de irrigação foram equivalentes a ETr calculada em função da evapotranspiração de referência $\left(\mathrm{ET}_{0}\right)$ estimada por meio do método FAO-24 da radiação (Frevert et al., 1983), corrigida para os valores de Kc da cultura e do coeficiente de umidade do solo (Ks) (Bernardo et al., 2005).

O balanço de água no solo foi realizado empregando a equação:

$\mathrm{ETr}=\mathrm{I}-\Delta \mathrm{U}-\mathrm{D}$
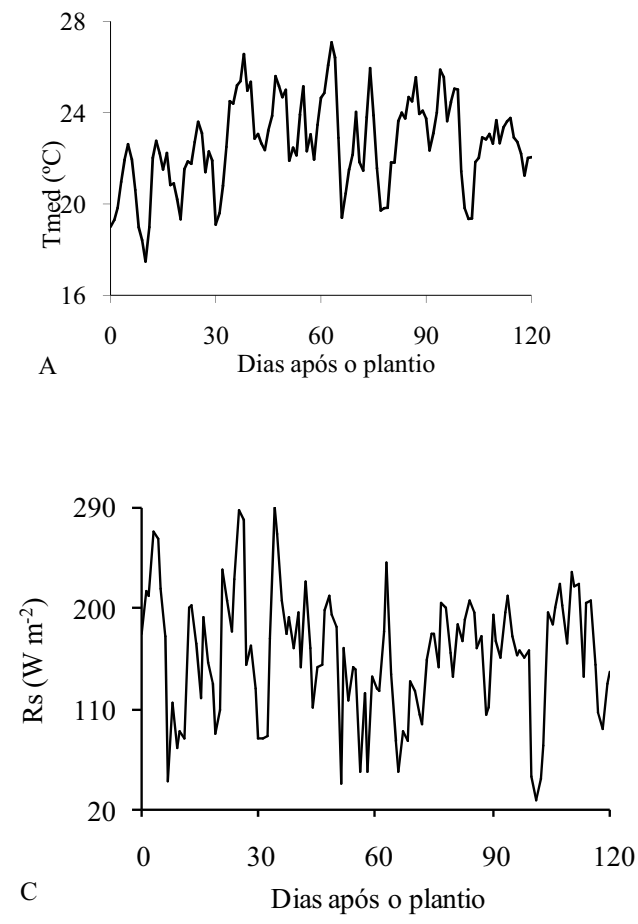
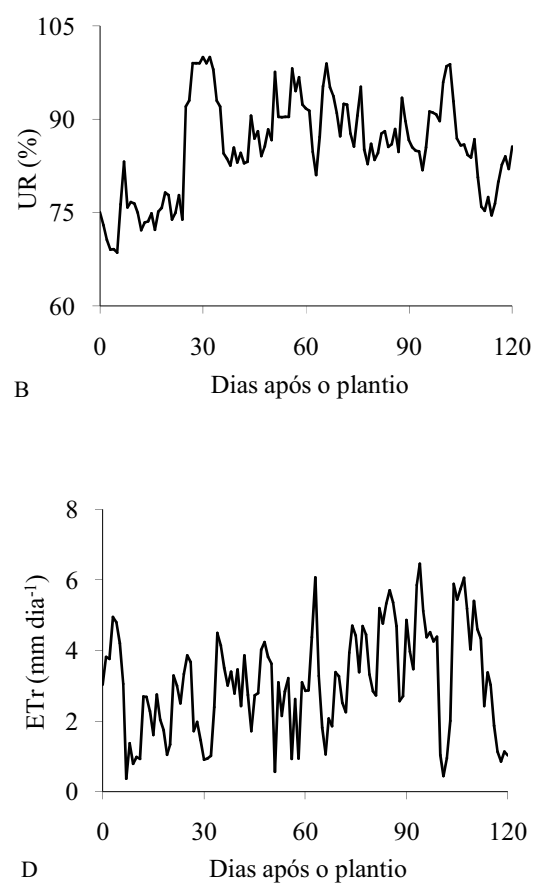

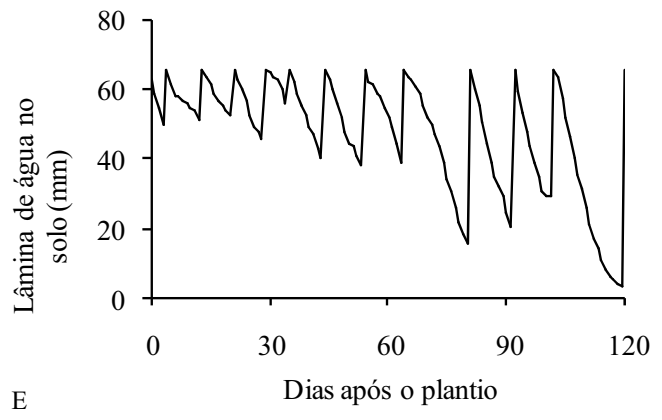

Figura 1. Valores médios diários de temperatura (A), umidade relativa (B), radiação solar incidente (C), evapotranspiração real (D) e o balanço de água no solo (E) durante o período experimental de cultivo da cultura do milho. 
Em que: I - lâmina de irrigação (mm); $\Delta \mathrm{U}$ variação do conteúdo de água no solo $(\mathrm{mm}), \mathrm{e} ; \mathrm{D}$ - lâmina de percolação profunda (mm).

A variedade de milho empregada no experimento foi a UFVM 100, sendo o plantio feito manualmente, em sulcos espaçados $0,70 \mathrm{~m}$ entre si, com 16 sementes por metro linear de sulco, perfazendo um total de 32 sementes por lisímetro no momento de plantio. Aos 15 DAP foi feito o desbaste permanecendo oito plantas por lisímetro (50.000 plantas ha-1).

Todos os tratamentos receberam a mesma adubação química de plantio que constituiu de 30 $\mathrm{Kg} \mathrm{ha}^{-1}$ de N, na forma de sulfato de amônio, 50 $\mathrm{Kg} \mathrm{ha}^{-1}$ de $\mathrm{P}$, na forma de superfosfato simples e $80 \mathrm{Kg} \mathrm{ha}^{-1} \mathrm{de} \mathrm{K}$, na forma de cloreto de potássio. Aos 30, 45 e 60 dias após o plantio (DAP) foram feitas três adubações nitrogenadas de cobertura na dose de $30 \mathrm{Kg} \mathrm{ha}^{-1}$, na forma se sulfato de amônio, e uma potássica na dose de $20 \mathrm{~kg} \mathrm{ha}^{-1}$, na forma de cloreto de potássio.

O controle de ervas daninhas foi feito com capinas manuais enquanto o controle de Spodoptera frugiperda se deu com a aplicação do inseticida piretróide "Decis", na dosagem de $0,3 \mathrm{~L} \mathrm{ha}^{-1}$.

As frações de lixiviação foram aplicadas a partir dos 30 DAP, enquanto no período inicial foram aplicadas apenas as lâminas de irrigação de manutenção da umidade do solo. A lâmina de irrigação correspondente a ETr, acrescida da fração de lixiviação de cada tratamento foi aplicada manualmente e de forma uniforme, em cada lisímetro.

Os efeitos da salinidade da solução do solo sobre a nutrição mineral da cultura do milho foram avaliados determinando o teor foliar dos macronutrientes catiônicos e suas relações com o sódio. Para tanto, nas fases fenológicas do período vegetativo, floração, formação da colheita e maturação fisiológica, correspondente aos 30, 60, 90 e $120 \mathrm{DAP}$, respectivamente, foram coletadas aleatoriamente, em diferentes plantas de cada unidade experimental, três folhas localizadas abaixo da inserção da espiga, sendo encaminhas ao laboratório para a realização das análises conforme descrito por Fontes (2001). Aos 30 DAP foi coletada a quarta folha totalmente expandida.

Paralelamente as coletas das folhas para as análises, foram retiradas de cada unidade experimental amostras de solo nas camadas de 0-20, 20-40 e 40-60 cm, para a determinação do balanço de sais no perfil do solo, avaliado a partir da medição da condutividade elétrica do solo saturado. A condutividade elétrica foi determinada por leitura direta, na solução extraída da pasta de solo saturada, com auxílio um condutivímetro (Ruiz, 2003).

Os dados foram analisados por meio de análise de variância e de regressão. Os modelos foram escolhidos com base na significância dos coeficientes de regressão, utilizando o teste " $t$ " e adotando-se $\alpha$ máximo de até $5 \%$, no coeficiente de determinação $\left(\mathrm{r}^{2}\right)$ e no fenômeno em estudo.

\section{RESULTADOS E DISCUSSÃO}

\section{SALINIDADE DO SOLO}

Os níveis médios de salinidade do solo (Tabela 3) aos 30 DAP não excedem a salinidade limiar, para a cultura do milho, de $1,70 \mathrm{dS} \mathrm{m}^{-1}$ capaz de induzir uma diminuição sensível no rendimento. Por outro lado, conforme os critérios estabelecidos por Ayers \& Wetscot (1991), a partir dos 60 DAP os níveis médios de salinidade do solo já são capazes de induzir uma redução potencial na ordem de 10 a $50 \%$ no rendimento da cultura.

Os resultados médios da salinidade do extrato da pasta saturada do solo (CEes) em função das frações de lixiviação e da condutividade elétrica da água de irrigação apresentados na Tabela 3, aumentaram ao longo dos períodos de avaliação da cultura, enquanto, a medida que as frações de lixiviação diminuíram dentro de cada período analisado, exceto aos 30DAP, a salinidade do extrato de saturação do solo aumentou. Esse resultado comprova que a lixiviação resultante da passagem de água através do perfil do solo é uma prática eficaz para reduzir o excesso de sais solúveis na zona radicular das culturas.

Considerado uma espécie moderadamente tolerante à salinidade, a cultura do milho sofre como tal, redução progressiva do crescimento, com o aumento da concentração de sais no meio radicular. A maior sensibilidade da cultura ao estresse salino, ocorre no período vegetativo e a maior tolerância na época de floração, não sendo relatado nenhum efeito sobre a germinação (Izzo et al., 1991).

\section{CÁLCIO}

A salinidade do solo afetou significativamente os teores de cálcio nas folhas de milho aos 30 e 120 DAP (Tabela 4). A Figura 2A mostra respectivamente o decréscimo do teor de cloro nas folhas de milho com o aumento dos níveis de salinidade do solo. 
Tabela 3

Valores médios da condutividade elétrica do extrato de saturação no perfil do solo determinados nas unidades experimentais aos 30, 60, 90 e 120 DAP

\begin{tabular}{|l|c|c|c|c|c|}
\hline \multirow{2}{*}{ Tratamentos } & \multicolumn{5}{|c|}{ Condutividade elétrica do extrato de saturação do solo $\left(\mathbf{d S} \mathbf{~ m}^{-\mathbf{1}}\right)$} \\
\cline { 2 - 6 } & $\mathbf{3 0}$ DAP & $\mathbf{6 0 ~ D A P}$ & $\mathbf{9 0}$ DAP & $\mathbf{1 2 0}$ DAP & Média \\
\hline AD & 0,81 & 0,85 & 0,81 & 0,85 & 0,83 \\
\hline ASFL 40\% & 1,27 & 1,67 & 2,55 & 3,21 & 2,17 \\
\hline ASFL 30\% & 1,13 & 1,74 & 2,92 & 4,07 & 2,47 \\
\hline ASFL 20\% & 1,29 & 1,96 & 3,29 & 4,67 & 2,80 \\
\hline ASFL 15\% & 1,10 & 2,10 & 3,58 & 5,18 & 2,99 \\
\hline ASFL 10\% & 1,18 & 2,53 & 4,05 & 6,57 & 3,58 \\
\hline ASFL 05\% & 1,39 & 3,01 & 5,01 & 7,89 & 4,33 \\
\hline
\end{tabular}

AD - Água doce; ASFL - Água salina acrescida com a fração de lixiviação.

Tabela 4

Resumo da análise de variância das variáveis cálcio, magnésio, potássio e sódio em função da salinidade do solo aos 30, 60, 90 e 120 DAP

\begin{tabular}{|c|c|c|c|c|c|}
\hline \multirow{2}{*}{ Fonte de variação } & \multirow{2}{*}{ GL } & \multicolumn{4}{|c|}{ Quadrados Médios } \\
\hline & & 30 DAP & 60 DAP & 90 DAP & 120 DAP \\
\hline \multicolumn{6}{|c|}{ Cálcio } \\
\hline Tratamentos & 6 & $0,1028^{\text {ns }}$ & $0,0115^{\mathrm{ns}}$ & $0,0575^{\mathrm{ns}}$ & $0,0209 *$ \\
\hline Resíduo & 14 & 0,1022 & 0,0091 & 0,0542 & 0,0005 \\
\hline \multicolumn{2}{|l|}{ Coeficiente de variação (\%) } & 21,33 & 21,79 & 29,28 & 2,99 \\
\hline \multicolumn{6}{|c|}{ Magnésio } \\
\hline Tratamentos & 6 & $0,0015^{\mathrm{ns}}$ & $0,0107 *$ & $0,0103^{*}$ & $0,0030^{*}$ \\
\hline Resíduo & 14 & 0,0011 & 0,0022 & 0,0031 & 0,0001 \\
\hline \multicolumn{2}{|l|}{ Coeficiente de variação (\%) } & 18,82 & 29,89 & 28,09 & 5,20 \\
\hline \multicolumn{6}{|c|}{ Potássio } \\
\hline Tratamentos & 6 & $0,1269^{\text {ns }}$ & $0,0071^{\mathrm{ns}}$ & $0,0858^{\mathrm{ns}}$ & $0,1737 *$ \\
\hline Resíduo & 14 & 0,1659 & 0,0193 & 0,0586 & 0,0054 \\
\hline \multicolumn{2}{|l|}{ Coeficiente de variação (\%) } & 14,07 & 10,43 & 18,03 & 6,52 \\
\hline \multicolumn{6}{|c|}{ Sódio } \\
\hline Tratamentos & 6 & $0,0005^{*}$ & $0,6334^{*}$ & $0,4499^{*}$ & $0,6630^{*}$ \\
\hline Resíduo & 14 & 0,0002 & 0,1009 & 0,0253 & 0,0028 \\
\hline \multicolumn{2}{|l|}{ Coeficiente de variação (\%) } & 17,20 & 27,95 & 12,04 & 3,88 \\
\hline
\end{tabular}

ns - não significativo; * significativo a 5\% de probabilidade. 
Tabela 5

Coeficientes de correlação entre os teores de sódio com o cálcio, magnésio e potássio nas folhas de milho aos 30, 60, 90 e 120 DAP

\begin{tabular}{|l|l|c|c|c|}
\hline \multicolumn{1}{|c|}{ Variáveis } & Coeficiente de correlação & Valor de t & Probabilidade $>$ t \\
\hline \multicolumn{5}{|c|}{ 30 } \\
\hline Sódio & Cálcio & $-0,4779$ & 2,6315 & 0,0082 \\
\hline Sódio & Magnésio & $-0,2389$ & 1,0723 & 0,1485 \\
\hline Sódio & Potássio & $-0,1886$ & 0,6551 & 0,2601 \\
\hline \multicolumn{5}{|c|}{$\mathbf{6 0}$ DAP } \\
\hline Sódio & Cálcio & $-0,5168$ & 2,3716 & 0,0144 \\
\hline Sódio & Magnésio & $-0,4718$ & 2,9109 & 0,0045 \\
\hline Sódio & Potássio & $-0,4585$ & 2,2488 & 0,0183 \\
\hline \multicolumn{5}{|c|}{$\mathbf{9 0}$ DAP } \\
\hline Sódio & Cálcio & $-0,6731$ & 3,9998 & 0,0004 \\
\hline Sódio & Magnésio & $-0,5554$ & 2,3321 & 0,0154 \\
\hline Sódio & Potássio & $-0,6068$ & 3,3273 & 0,0018 \\
\hline & \multicolumn{5}{|c|}{$\mathbf{1 2 0}$ DAP } \\
\hline Sódio & Cálcio & $-0,9145$ & 9,8499 & 0,0001 \\
\hline Sódio & Magnésio & $-0,8731$ & 7,8053 & 0,0001 \\
\hline Sódio & Potássio & $-0,8688$ & 7,6497 & 0,0001 \\
\hline
\end{tabular}

Apesar da tendência de diminuição dos teores de cálcio nas folhas aos 120 DAP os resultados obtidos, nesta fase de avaliação da cultura são considerados adequados, conforme os critérios estabelecidos por Taiz \& Zeiger (2004) de $0,32 \mathrm{dag} \mathrm{kg}^{-1}$ mostrando assim existir, uma relação definida entre o crescimento da planta e o teor de nutrientes em seus tecidos. Por sua vez, os teores adequados de cálcio nas folhas de milho foram devidos ao suprimento desse elemento pelo solo, evidenciados pelos valores no Tabela 1 e também pela adição deste nutriente ao solo via água de irrigação (Tabela 2).

Estudos têm demonstrado que a salinidade diminui os teores de cálcio na parte aérea das plantas de milho (Alberico \& Cramer, 1991; Cramer et al., 1994; Azevedo Neto \& Tabosa 2000). Semelhantemente a este trabalho, estes autores reportaram que o aumento do teor de sódio do meio externo ocasiona a diminuição dos teores de cálcio nos tecidos das plantas de milho, pois o sódio desloca o cálcio do plasmalema das células radiculares, o que resulta em uma perda da integridade da membrana e efluxo citossólico de solutos orgânicos e inorgânicos (Cramer et al., 1994).

As alterações nas membranas onde o cálcio é um íon estabilizante pode conduzir uma sensibilidade maior da cultura ao estresse salino, haja vista a seletividade das membranas nos processos de absorção e compartimentação iônica (Azevedo Neto \& Tabosa, 2000).

Trabalhos com plantas sob estresse salino tem demonstrado que a suplementação de cálcio reduz a acumulação de sódio e mantém os níveis de potássio e metabólicos fosfatados nos tecidos radiculares, além de reduzir as perdas de fósforo (Colmer et al., 1994).

\section{MAGNÉSIO}

A salinidade do solo afetou significativamente os teores de magnésio nas folhas de milho aos 60 , 90 e 120 DAP (Tabela 4). A Figura 2 B, C e D 


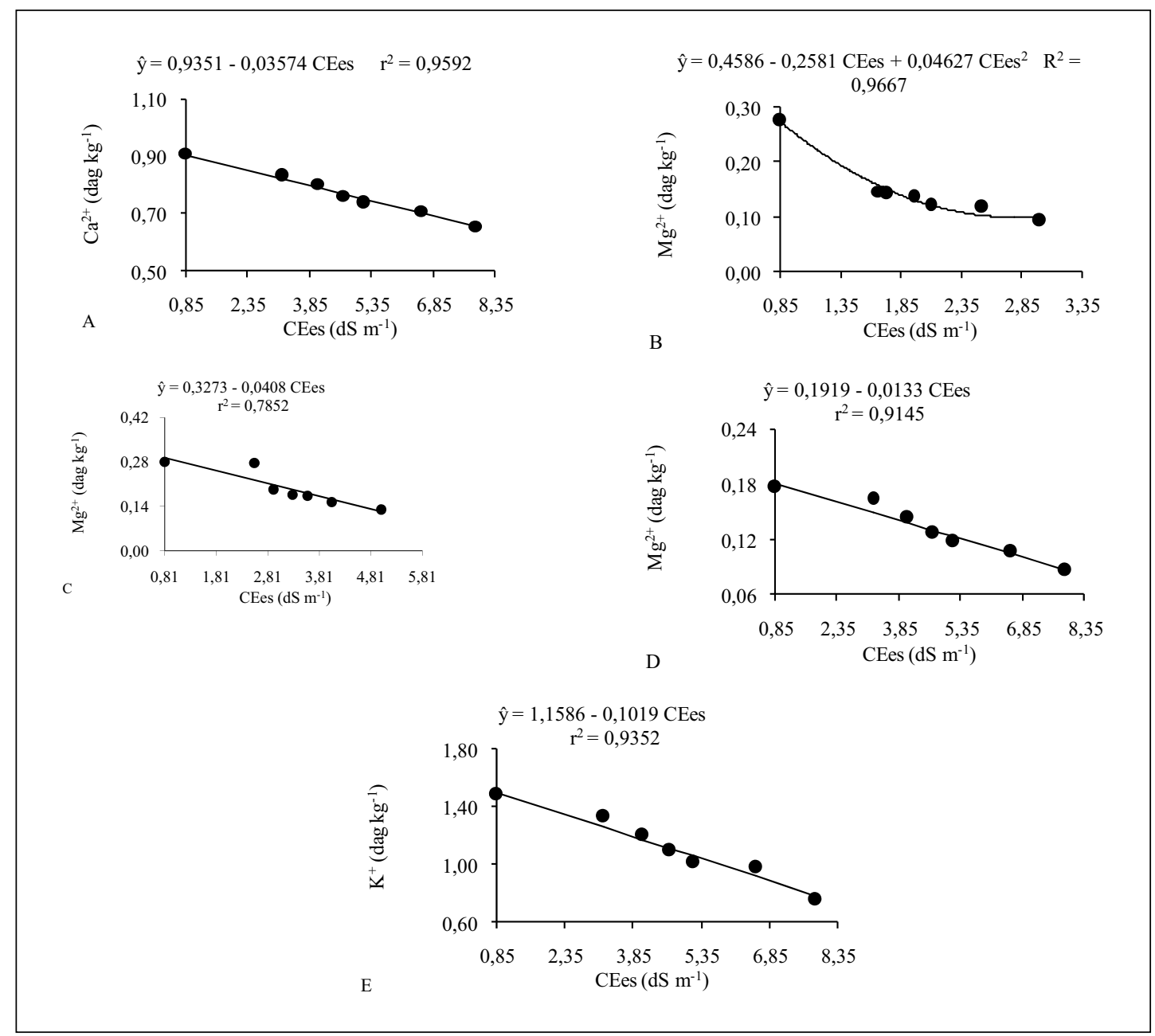

Figura 2. Teor de cálcio aos 120 DAP $\left(\mathrm{Ca}^{2+}\right)(\mathrm{A})$, magnésio $\left(\mathrm{Mg}^{2+}\right)$ aos $60(\mathrm{~B}), 90(\mathrm{C})$ e $120(\mathrm{D})$ e potássio $\left(\mathrm{K}^{+}\right)$aos $120 \mathrm{DAP}(\mathrm{E})$ nas folhas de milho em função dos níveis de salinidade do solo (CEes).

mostra respectivamente, o decréscimo do teor de magnésio nas folhas de milho com o aumento dos níveis de salinidade do solo.

Os teores de magnésio nas folhas das plantas de milho estão abaixo de $0,40 \mathrm{dag} \mathrm{kg}^{-1}$, conforme estabelecido por Taiz \& Zeiger (2004) como adequados para a cultura. Em adição a este trabalho, Azevedo Neto \& Tabosa (2000) verificaram em plantas de milho, submetidas a diferentes níveis de $\mathrm{NaCl}$ em solução nutritiva, a diminuição dos teores de magnésio na raiz e no colmo, exceto na bainha e no limbo onde os teores de magnésio permaneceram relativamente constantes.

Além do papel do magnésio na atividade como co-fator em quase todas as enzimas do metabolismo energético e na molécula de clorofila, este íon é requerido para a integridade dos ribossomos e contribui efetivamente para a estabilidade estrutural dos ácidos nucléicos e membranas (Taiz \& Zeiger, 2004). Apesar da importância do magnésio no metabolismo vegetal, a literatura referente a estudos sobre as concentrações deste nutriente em plantas cultivadas sob estresse salino é bastante limitada, tanto para milho, como para outras espécies.

\section{POTÁSSIO}

Os íons de potássio desempenham um importante papel na regulação do potencial osmótico das células vegetais, além de ativar muitas enzimas envolvidas na respiração e na fotossíntese (Taiz \& Zeiger, 2004). 
A Figura 2 E mostra que salinidade do solo afetou significativamente os teores de potássio nas folhas de milho aos 120 DAP (Tabela 4) decrescendo linearmente seus valores com o aumento dos níveis de salinidade do solo.

Estudos têm demonstrado que a salinidade do solo diminui os teores de potássio na parte aérea das plantas de milho (Alberico \& Cramer, 1991; Cramer et al., 1994; Azevedo Neto \& Tabosa, 2000). Semelhante a este trabalho, estes autores reportaram que o aumento da concentração de sódio do meio externo ocasiona a diminuição dos teores de potássio nos tecidos das plantas e milho, pois o aumento da concentração de sódio no meio radicular pode inibir a absorção de potássio devido a relação competitiva entre estes cátions monovalentes (Kawasaki et al., 1983).

O estresse salino promove aumento no efluxo citossólico de potássio nas raízes das plantas, esta perda pode ser o resultado direto de trocas osmoticamente induzidas na permeabilidade do plasmalema, como também da substituição de cálcio por sódio na membrana, abrindo canais para o potássio (Azevedo Neto \& Tabosa, 2000).

\section{SÓDIO}

A Figura 3 A, B, C e D, mostra respectivamente, que a salinidade do solo afetou significativamente os teores de sódio nas folhas de milho aos 30, 60, 90 e 120 DAP (Tabela 4), aumentando seus valores com o aumento dos níveis de salinidade do solo.

A maioria das espécies que utiliza as rotas $\mathrm{C}_{4}$ de fixação do carbono requerem íons sódio. Nestas plantas, o sódio parece ser vital para a regeneração do fosfoenolpiruvato, substrato da primeira carboxilação nas rotas $\mathrm{C}_{4}$, além de estimular o crescimento por meio de uma maior expansão celular e, ainda, substituir parcialmente o potássio como um soluto osmoticamente ativo (Marschner, 2000).

O teor de sódio nas folhas da plantas de milho aumentaram consideravelmente com o incremento dos níveis de salinidade do solo. Por sua vez, notase que aos 90 e 120 DAP houve uma tendência de estabilização nos teores de sódio nos níveis mais elevados de salinidade do solo, o que pode representar uma compartimentação a nível celular, haja vista a não identificação da real locação do
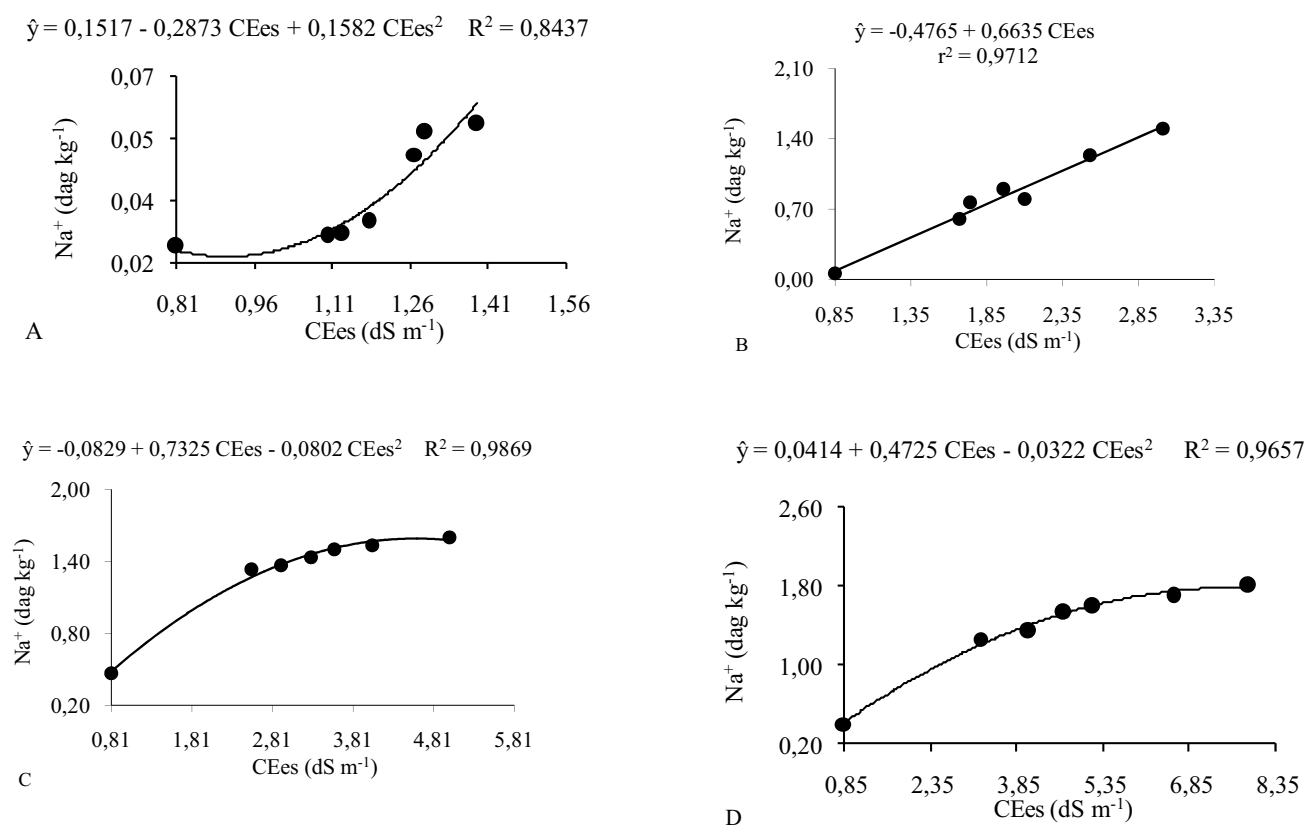

Figura 3. Teor de sódio $\left(\mathrm{Na}^{+}\right)$nas folhas de milho aos 30 (A), 60 (B), 90 (C) e 120 (D) DAP em função dos níveis de salinidade do solo (CEes). 
Tabela 6

Resumo da análise de variância das variáveis relação $\mathrm{Na}^{+} / \mathrm{Ca}^{2+}, \mathrm{Na}^{+} / \mathrm{Mg}^{2+} \mathrm{e} \mathrm{Na} / \mathrm{K}^{+}$ em função da salinidade do solo aos 30, 60, 90 e 120 DAP

\begin{tabular}{|c|c|c|c|c|c|}
\hline \multirow{2}{*}{ Fonte de variação } & \multirow{2}{*}{ GL } & \multicolumn{4}{|c|}{ Quadrados médios } \\
\hline & & 30 DAP & 60 DAP & 90 DAP & 120 DAP \\
\hline \multicolumn{6}{|c|}{ Relação $\mathrm{Na}^{+} / \mathrm{Ca}^{2+}$} \\
\hline Tratamentos & 6 & $0,0038 *$ & $2,1074 *$ & $8,4383^{\mathrm{ns}}$ & $1,6769^{*}$ \\
\hline Resíduo & 14 & 0,0004 & 0,2011 & 4,5136 & 0,0105 \\
\hline \multicolumn{2}{|l|}{ Coeficiente de variação (\%) } & 14,42 & 20,79 & 28,90 & 5,55 \\
\hline \multicolumn{6}{|c|}{ Relação $\mathrm{Na}^{+} / \mathbf{M g}^{2+}$} \\
\hline Tratamentos & 6 & $0,0262 *$ & $79,7457^{*}$ & $60,5315^{*}$ & $107,8518 *$ \\
\hline Resíduo & 14 & 0,0058 & 5,4349 & 26,1641 & 0,9704 \\
\hline \multicolumn{2}{|l|}{ Coeficiente de variação (\%) } & 14,84 & 28,82 & 29,89 & 8,41 \\
\hline \multicolumn{6}{|c|}{ Relação $\mathrm{Na}^{+} / \mathrm{K}^{+}$} \\
\hline Tratamentos & 6 & $0,0002 *$ & $0,6057^{*}$ & $0,4223 *$ & $1,4041^{*}$ \\
\hline Resíduo & 14 & 0,0001 & 0,0175 & 0,0716 & 0,5167 \\
\hline \multicolumn{2}{|l|}{ Coeficiente de variação (\%) } & 25,95 & 16,32 & 25,51 & 16,75 \\
\hline
\end{tabular}

ns - não significativo; * significativo a $5 \%$ de probabilidade.

sódio nas células das folhas no presente trabalho, reduzindo assim a toxicidade por este íon nos sítios metabolicamente ativos das folhas.

O aumento da concentração de sódio na parte aérea de plantas de milho cultivado em ambientes salinos, tem sido estudados por vários pesquisadores. Semelhantemente ao observado neste trabalho Willadino et al., (1994); Azevedo Neto \& Tabosa (2000); Azevedo Neto et al. (2004) observaram aumentos nos teores de sódio nas folhas de milho cultivados em ambientes salinos.

\section{RELAÇÃO DO SÓDIO COM O CÁLCIO $\left(\mathrm{NA}^{+} /\right.$} $\left.\mathrm{CA}^{2+}\right)$, MAGNÉSIO $\left(\mathrm{NA}^{+} / \mathrm{MG}^{2+}\right)$ E POTÁSSIO $\left(N A^{+} / K^{+}\right)$

A determinação das relações do sódio com o cálcio, magnésio e potássio, $\left(\mathrm{Na}^{+} / \mathrm{Ca}^{2+}, \mathrm{Na}^{+} / \mathrm{Mg}^{2+} \mathrm{e}\right.$ $\mathrm{Na}^{+} / \mathrm{K}^{+}$) revelam-se como importantes variáveis para a seleção de plantas tolerantes quando, nos estudos, os objetivos forem analisar o estado nutricional das plantas quando submetidas à salinidade (Azevedo Neto \& Tabosa, 2000).

A salinidade do solo aos 30, 60 e 120 DAP afetou significativamente as relações $\mathrm{Na}^{+} / \mathrm{Ca}^{2+}$ e $\mathrm{Na}^{+} / \mathrm{Mg}^{2+}$ nas folhas de milho (Tabela 5). A Figura 4 A, B, C, D, E e F, respectivamente, mostra o aumento das relações $\mathrm{Na}^{+} / \mathrm{Ca}^{2+} \mathrm{e} \mathrm{Na}^{+} / \mathrm{Mg}^{2+}$ nas folhas de milho, com o aumento dos níveis de salinidade do solo.

$\mathrm{O}$ aumento dos valores das relações $\mathrm{Na}^{+}$/ $\mathrm{Ca}^{2+} \mathrm{e} \mathrm{Na}^{+} / \mathrm{Mg}^{2+}$ nas folhas das plantas de milho com o incremento dos níveis de salinidade do solo, indicam o acréscimo na absorção de sódio em detrimento da absorção de cálcio e magnésio. Ao contrário dos 60 e 120 DAP (Figura 4 $\mathrm{B}, \mathrm{C}, \mathrm{E}$ e F respectivamente), as relações $\mathrm{Na}^{+}$/ $\mathrm{Ca}^{2+}$ e $\mathrm{Na}^{+} / \mathrm{Mg}^{2+}$ aos 30 DAP (Figura 4 A e D, respectivamente) não representou algum tipo de antagonismo entre os nutrientes ou mesmo evidenciou alguma toxicidade relativa ao íon sódio, pois tais relações iônicas com valores abaixo de 0,60 são considerados adequados para uma ótima eficiência metabólica em plantas não halófitas (Greenway \& Muns, 1980).

A manutenção de baixas relações $\mathrm{Na}^{+} / \mathrm{Ca}^{2+}$ e $\mathrm{Na}^{+} / \mathrm{Mg}^{2+}$ é considerada como um importante critério na caracterização da tolerância das plantas a salinidade (Saur et al., 1995). Uma relação $\mathrm{Na}^{+} /$ $\mathrm{Ca}^{2+}$ elevada, faz com que o $\mathrm{Na}^{+}$desloque o $\mathrm{Ca}^{2+}$ 


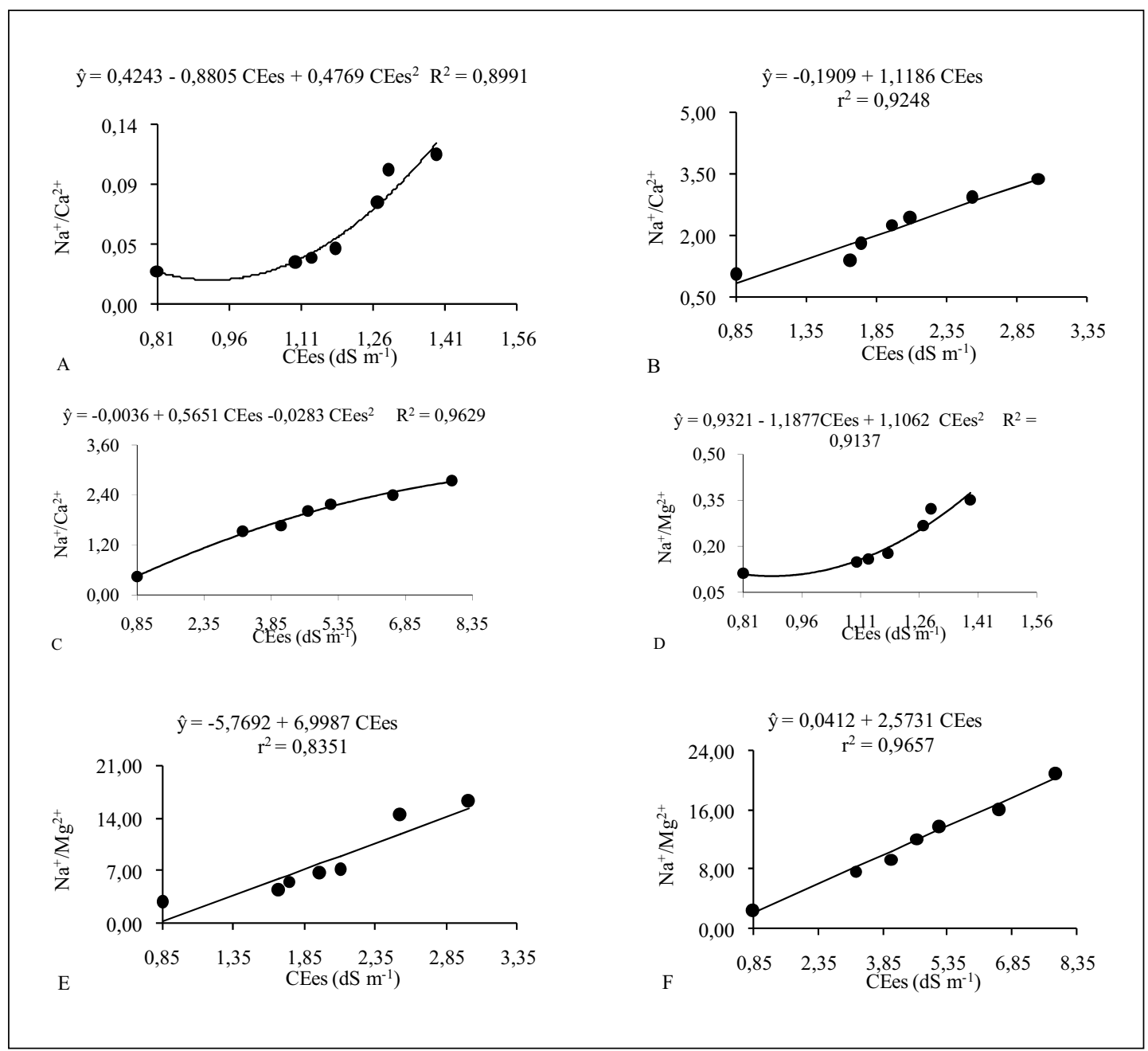

Figura 4. Relação do sódio cálcio $\left(\mathrm{Na}^{+} / \mathrm{Ca}^{2+}\right)$, magnésio $\left(\mathrm{Na}^{+} / \mathrm{Mg}^{2+}\right)$ nas folhas de milho aos 30 (A), 60 (B) e 120 (C) DAP.em função dos níveis de salinidade do solo (CEes).

da membrana celular, induzindo a perda de sua integridade resultando no desequilibro na absorção iônica (Marschner, 2000) e redução da seletividade de $\mathrm{Na}^{+}-\mathrm{Ca}^{2+}$ e $\mathrm{Na}^{+}-\mathrm{Mg}^{2+}$ nas raízes (Azevedo Neto \& Tabosa, 2000).

A literatura evidencia que o aumento da concentração de sódio no ambiente radicular das plantas, promove a elevação das relações $\mathrm{Na}^{+} / \mathrm{Ca}^{2+} \mathrm{e} \mathrm{Na}^{+} /$ $\mathrm{Mg}^{2+}$. Nesse contexto, Azevedo Neto \& Tabosa (2000) verificaram o aumento das relações $\mathrm{Na}^{+} /$ $\mathrm{Ca}^{2+} \mathrm{e} \mathrm{Na}^{+} / \mathrm{Mg}^{2+}$ no limbo, raiz, colmo e bainha de plântulas de milho com o incremento dos níveis de $\mathrm{NaCl}$, em solução nutritiva.

A relação $\mathrm{Na}^{+} / \mathrm{K}^{+}$é um dos fatores que está intimamente relacionado ao grau de tolerância das culturas a salinidade, podendo ser utilizada como índice para toxicidade de sódio, devido ao fato deste íon inibir a atividade das enzimas que requerem potássio (Greenway \& Muns, 1980).

A Figura 5 A, B, C e D mostra que a salinidade afetou significativamente a relação $\mathrm{Na}^{+} / \mathrm{K}^{+}$nas folhas das plantas de milho aos 30, 60, 90 e 120 DAP, aumentando seus valores com o incremento dos níveis de salinidade do solo.

Observando a relação $\mathrm{Na}^{+} / \mathrm{K}^{+}$aos 60,90 e 120 DAP (Figura 5 B, C e D respectivamente) nota-se que seus valores crescem linearmente com o incremento dos níveis de salinidade do solo evidenciando a maior absorção e translocação de sódio, em relação ao potássio com o incremento dos níveis de salini- 
dade do solo, refletindo a sensibilidade da cultura ao estresse salino, a indução de um desequilíbrio iônico nas plantas e consequientemente uma menor eficiência metabólica das folhas.

Exceto aos $30 \mathrm{DAP}$ (Figura $5 \mathrm{~A}$ ) a relação $\mathrm{Na}^{+} /$ $\mathrm{K}^{+}$nas folhas das plantas de milho, excede o valor de 0,6 considerado por (16), como o necessário para uma ótima eficiência metabólica em plantas não-halófitas.

É reconhecida à importância do $\mathrm{Na}^{+}$para as plantas de metabolismo fotossintético $\mathrm{C}_{4}$, sendo citado por Taiz \& Zeiger (2004) como um micronutriente para elas, no entanto tem-se verificado que, altas concentrações, $\mathrm{o} \mathrm{Na}^{+}$diminuem a absorção do $\mathrm{K}^{+}$(Willadino et al., 1994).

Estudos têm indicado o efeito competitivo entre $\mathrm{Na}^{+}$e $\mathrm{K}^{+}$assim como a seletividade por estes íons e sua relação com a sensibilidade das plantas à salinidade (Willadino et al., 1999; Azevedo Neto \& Tabosa, 2000; Azevedo Neto et al., 2004). Os autores verificaram aumento da relação $\mathrm{Na}^{+} / \mathrm{K}^{+}$na parte aérea de plantas de milho com o incremento dos níveis de $\mathrm{NaCl}$ em solução nutritiva. Segundo esses autores, o desequilibro na absorção iônica em decorrência do aumento dos valores da relação $\mathrm{Na}^{+}$/
$\mathrm{K}^{+}$, reduziu a seletividade dos íons de $\mathrm{K}^{+}$nas raízes devido a perda da integridade das membranas sob condições de salinidade.

Analisando os teores dos macronutrientes catiônicos nas folhas das plantas de milho ao longo do ciclo da cultura, observa-se que houve diminuição progressiva dos teores de cálcio, magnésio e potássio juntamente com o aumento dos teores de sódio.

Assim como ocorreu entre os macronutrientes aniônicos, verificou-se um possível antagonismo progressivo entre estes nutrientes, o qual é mostrado, por meio dos valores de correlação negativa (Tabela 6) obtidos durante os períodos de avaliação da cultura, confirmando a hipótese da diminuição dos teores de cálcio, magnésio e potássio nos tecidos das plantas de milho estarem geralmente associado ao aumento progressivo dos teores de sódio.

\section{CONCLUSÕES}

Na variedade de milho UFVM 100 avaliada, o aumento dos níveis de salinidade do solo decorrentes da irrigação com água salina:

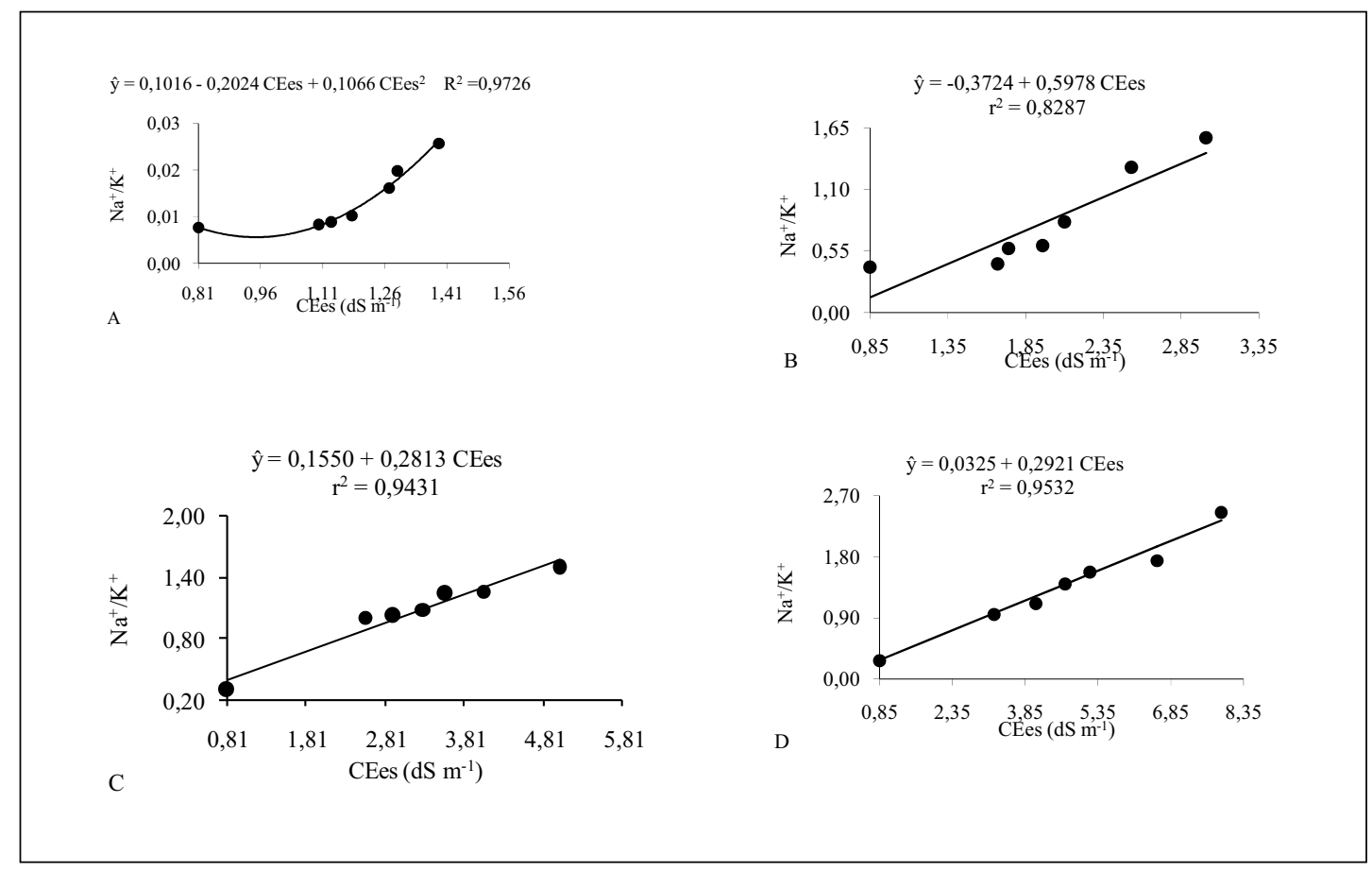

Figura 5. Relação sódio potássio $\left(\mathrm{Na}^{+} / \mathrm{K}^{+}\right)$nas folhas de milho aos 30 (A), 60 (B), 90 (C) e 120 (D) DAP em função dos níveis de salinidade do solo (CEes). 
- Elevou os teores de sódio nas folhas, seguido da redução dos teores de cálcio, magnésio e potássio ao longo do ciclo da cultura refletindo o desequilíbrio nutricional causado pelo estresse nutricional conseqüente do estresse salino progressivo;

- Eleva as relações $\mathrm{Na}^{+} / \mathrm{Ca}^{2+}, \mathrm{Na}^{+} / \mathrm{Mg}^{2+} \mathrm{e} \mathrm{Na}^{+} /$ $\mathrm{K}^{+}$nas folhas, mostrando-se como importantes

\section{REFERÊNCIAS BIBLIOGRAFICAS}

ALBERICO, G.J., CRAMER, G.R. 1991. Is the salt tolerance of maize related to sodium exclusion I. Preliminary screening of seven cultivars. Journal Plant Nutrition. 16: 2289-2303.

AYERS, R.S.; WESTCOT, D.W. 1991. A qualidade da água na agricultura. Campina Grande, UFPB, 218 p. (Boletim $\mathrm{n}^{\circ} 29$ ).

AZEVEDO NETO, A.D.; TABOSA, J.N. 2000. Estresse salino em plântulas de milho: Parte II distribuição dos macronutrientes catiônicos e suas relações com o sódio. Revista Brasileira de Engenharia Agrícola e Ambiental. 4 (2):165-171.

AZEVEDO NETO, A.D.; TABOSA, J.N.; ENEAS-FILHO, J.; LACERDA, C.F.; SILVA, J.V.; COSTA, P.H.C; GOMES FILHO, E. 2004. Effects salt stress on plant growth, stomatal response and solute accumulation of different maize genotypes. Brazilian Journal Plant Physiology. 16 (1):31-38.

BERNARDO, S.; MANTOVANI, E.C.; SOARES, A.A. 2005. Manual de irrigação. 7a. ed. Viçosa, UFV, 611 p.

BOURSIER, P.; LYNCH, J.; LÄUCHLI, A.; EPSTEIN, E. 1987. Chloride partioning in leaves of salt-stressed sorghum, maize, wheat and barley. Australian Journal of Plant Physiology, 14: 463-473.

CHEESEMAN, J.M. Mechanisms of salinity tolerance in plants. (1998) Plant Physiology, 87:547-550.

COLMER, T.D.; FAN, T.W.M.; HIGASHI, R.M.; LÄUCHLI, A. 1994. Interactions of $\mathrm{Ca}^{2+}$ and $\mathrm{NaCl}$ stress on the relations and intracellular $\mathrm{pH}$ of Sorghum bicolor root tips: An in vivo 31P-NMR study. Journal of Experimental Botany, 45: 1037-1044.

CRAMER, G.R.; ALBERICO, G.J.; SCHMIDT, C. Salt tolerance is not associated with the sodium accumulation of two maize hybrids. Australian Journal of Plant Physiology, 21: 675-692.

EMBRAPA. 1994. - Empresa Brasileira de Pesquisa Agropecuária. (1997) Manual de métodos de análise de solo. $2^{\mathrm{a}}$ ed. Rio de Janeiro, CNPS, 212 p.

FONTES, P.C.R. 2001. Diagnóstico do estado nutricional das plantas. Ed. UFV, Viçosa. $122 \mathrm{p}$

FLORES, H.E. 1990. Polyamines and plant stress In: LASCHER, R.G.; CUMMING, J.R. Stress responses in plants: adaptation and acclimation mechanisms. New York, Wiley-liss, p. 217-39.

FREVERT, D.R.; HILL, R.W.; BRAATEN, B.C. 1983. Estimation of FAO evapotranspiration coefficients. Journal of Irrigation and Drainage. 109: 265-270. variáveis no estudo nutricional das plantas sob condições de salinidade.

\section{AGRADECIMENTOS}

Os autores agradecem ao Conselho Nacional de Desenvolvimento Científico e Tecnológico-CNPq, pelo apoio financeiro.

GRATTAN, S. R.; GRIEVE, C. M. 1999. Salinity-mineral relations in horticultural crops. Scientia Horticulturae, 78:127-157.

GRATTAN, S.R., LAMENTA, M. 1994. Mineral nutrient acquisition and response by plants grown in saline environments. In: Pessarakli, M. (Ed.), Handbook of Plant and Crop Stress. New York, Marcel Dekker, p. 203-226.

GREENWAY, H.; MUNS, R. 1980. Mechanisms of salt tolerance in crop plants. Plant Physiology. 31:149-190.

IZZO, R.; NAVARI-IZZO, F.; QUARTACCI, F. 1991 Growth and mineral absorption in Maize seedling as affected by increasing $\mathrm{NaCl}$ concentrations. Journal of Plant Nutrition, 14:687-699.

KAWASAKI, T.; AKIBA, T.; MORITSUGU, M. 1983. Effects of high concentrations of sodium chloride and polyethylene glycol on the growth and ion absorption in plants: I. Water culture experiments in a greenhouse. Plant and Soil, 75:75-85.

LARCHER, W. 2000. Ecofisiologia Vegetal. ed RiMa Artes e Textos, São Carlos, 531 p.

MARSCHNER, H. 1995. Mineral nutrition of higher plant. 2. ed. Academy, New York, 889 p.

MEDEIROS, J.F. 1992. Qualidade da água de irrigação e evolução da salinidade nas propriedades assistidas pelo gat, nos estados do RN, PB e CE. Dissertação de Mestrado, Campina Grande, PB, UFPB. 137 p.

MUNNS, R.; TERMAAT, A. 1986. Whole plant responses to salinity. Australian Journal of Plant Physiology, 13:143-160.

RUIZ, H.A. 2003. Métodos de análises físicas do solo. Apostila Acadêmica. Programa de Pós-Graduação em solos e nutrição de plantas, Universidade Federal de Viçosa, 2003, 53 p.

SAUR, E.; LAMBROT, C.; LOUSTAU, D.; ROTIVAL, N.; TRICHET, P. 1995. Growth and uptake of mineral elements in response to sodium chloride of three provenances of maritime pine. Journal of Plant Nutrition, 18:(2): 243-256.

TAIZ, L., ZEIGER, E. 2004. Fisiologia Vegetal. $3^{\mathrm{a}}$ ed., Artmed, Porto Alegre, 719 p.

VAN GENUCHTEN, M.T. 1980. A Closed-form equation for predicting the hydraulic conductivity of unsaturated soils. Soil Science Society American Journal, 44: 892-898.

WILLADINO, L.; CAMARA, T.R.; SANTOS, M.A.; TORNE, J.M. 1994. Obtenção de uma linhagem de milho tolerante ao estresse salino mediante a cultura de anteras. Pesquisa Agropecuária Brasileira, 30:1313-1318. 
WILLADINO, L.; MARTINS, M.H.B.; CAMARA, T.R.; ANDRADE, G.; ALVES, G.D. 1999. Resposta de genótipos de milho ao estresse salino em condições hidropônicas. Sciencia Agrícola, 56 (4): 1209-1213.
YAHYA, A. 1998. Salinity effects on growth and uptake and distribution on sodium and some essential mineral nutrients in sesame. Journal of Plant Nutrition, 21(2): 1439-1451. 